NBER WORKING PAPERS SERIES

\title{
OCCASIONAL INTERVENTIONS TO TARGET RATES \\ WITH A FOREIGN EXCHANGE APPLICATION
}

Karen K. Lewis

Working Paper No. 3398

\author{
NATIONAL BUREAU OF ECONOMIC RESEARCH \\ 1050 Massachusetts Avetuue \\ Cambridge, MA 02138 \\ July 1990
}

This paper is a significantly revised version of my working paper entitled, "Can Managed Float Interventions Make the Exchange Rate Resemble a Target Zone?" I am grateful for helpful suggestions from Giuseppe Bertola, Willem Buiter, Avinash Dixit, Ken Froot, Peter Garber, Michael Klein, Paul Krugman, Maury Obstfeld, Paulo Pesenti and from seminar participants at Brown University, the University of Chicago, Dartmouth, the International Monetary Fund, the National Bureau of Economic Research, Princeton University, and Yale University. I am also grateful to the Olin Foundation for research support. This paper is part of NBER's research program in International Studies. Any opinions expressed are those of the author and not those of the National Bureau of Economic Research. 
NBER Working Paper \#3398

July 1990

OCCASIONAL INTERVENTIONS TO TARGET RATES
WITH A FOREIGN EXCHANGE APPLICATION

ABSTRACT

This paper develops a framework for analyzing the effects upon rates when occasional central bank interventions try to keep rates near target levels. Interestingly, the threat of capital gains or losses induced by this stochastic intervention policy helps contain rates within implicit boundarles around the target level. More importantly, this intervention policy concentrates observations of the exchange rate around the target level and away from the implicit bands. In Monte Carlo simulations, sufficlently tight distributions for intervention around the target level 1mply that the bands are never reached in practice. As an application, the model is empirically evaluated using exchange rate and intervention observations following the 1987 Louvre accord. In these estimates, the probability of intervention never exceeds more than about .5 while the range of observed exchange rates remain far away from the implicit bands where the probability of intervention is one.

Karen $\mathrm{K}$. Lewis

National Bureau of Economic Research 1050 Massachusetts Avenue Gambridge, MA 02139 
Governments frequently target macroeconomic variables such as exchange rates and interest rates through a mixed policy of occasional interventions with otherwise floating rates. 1 Under the recent managed float, for example, monetary authorities allow exchange rates to be determined by market forces most of the time, only to intervene as rates deviate significantly from target levels. According to popular press accounts, the occasional nature of these large trades in the foreign exchange market appears to influence expectations by private market traders who face possible capital gains or losses from these events. If so, asset prices should reflect expected interventions to target rates. This type of asset price behavior may also be implicit in stock prices if large holders of particular stocks such as portfolio insurers make large trades when prices move significantly.

This paper develops a framework for analyzing the effects from occasional discrete trades or interventions that stop movements in rates from targeted levels. The analysis indeed shows that the perceived threat of occasional capital gains or losses induced by central bank intervention influences market trading. As rates move farther from target levels, market participants believe that interventions are more likely and therefore they trade on the basis of these expectations. For example, if the market believes central banks might intervene to keep the exchange rate from depreciating further, they will hold less foreign currency than they would if no intervention were possible. Further, when they believe that interventions are more likely the farther rates stray from their targetted levels, this threat of intervention implies a nonlinear relationship between rates and their fundamentals. Remarkably, this nonlinear relationship

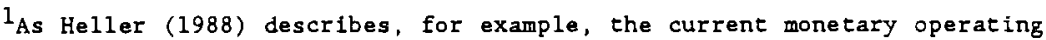
procedure represents a hybrid form of targetting interest rates and reserves. 
resembles the relationship found in models of "target zones" in the exchange rate literature. ${ }^{2}$

Although the theoretical relationship bears similarities to the "target zone" relationship, the empirical relationship looks very different. The differences may be summarized in two ways. First, the increasing threat of intervention away from the targetted level concentrates observations of the rate around this level. ${ }^{3}$ second, a policy that credibly backs up this threat implies that rates would effectively never reach the outer boundaries where interventions occur. For both of these reasons, standard tests would tend not pick up the true non-linear relationship between rates and fundamentals. 4 overall, the theoretical framework yields rich and intuitive empirical implications that should prove useful for understanding how occasional discrete large trades and interventions affect the behavior of asset prices.

This paper also empirically assesses the framework with an application to exchange rate intervention policy by the "Group of Three" (G-3) countries during the period 1985-1987.5 These interventions were chosen for empirical investigation since market observers seemed to view these events as uncertain in any given trading period. This uncertainty stemmed from at least two sources.

2 This model was introduced by Krugman (1990) and has been developed in the contest of fixed exchange rate arrangements by Froot and obstfeld (1989), Flood and Garber (1989), Bertola and Caballero (1989), Svensson (1989, 1990), Krugman (1989), Buiter and Grilli (1989), and Spencer (1990).

3 The target zone model implies that the asymptotic distribution of the exchange rate would be concentrated around the boundaries of the zone, and minimized at the target levels. See, for example, Svensson (1989).

${ }^{4}$ Meese and Rose (1990), for example, use non-parametric estimation to detect non-linearities in the exchange rate as implied by the standrard target zone model, but fail to find a significant relationship.

${ }^{5}$ The G-3 countries are the U.S., West Germany, and Japan. 
First, the U,S, government began intervening in 1985 for the first time in over four years. Thus, the market did not have recent experience with foreign exchange intervention policies. Second, the period was marked by policy statements, particularly after meetings by various groups of governments. Following these announcements, foreign exchange intervention policy sometimes appeared to change. The most notable case of such a policy change was the stabilization of exchange rates following the "Louvre Accord" in February 22 , 1987 .

The paper also demonstrates how the theoretical relationship between rates and thefr fundamentals may be backed out from observations of the rate and intervention. For the foreign exchange application, the theoretical relationship between the exchange rate and its fundamentals are empirically backed out using data on exchange rates and market observations of the forefgn exchange interventions by the G-3 central banks following the Louvre Accord. The evidence indicates that exchange rates were both (a) concentrated near their target levels, and (b) never approached boundary points where central banks would have intervened with probability one. Indeed, the probability of intervention never exceeded more than .5. This suggests that the threat of intervention played a role in stabilizing rates.

The plan of the paper is as follows. Section I develops a model to characterize market perceptions when central banks or other large players in the market occasionally trade in the market. This section also describes market observations of G-3 intervention during 1985 - 1987. Section II estimates a probability distribution for intervention policy and uses these estimates to infer the behavior of the exchange rate in terms of fundamentals. Concluding remarks and a discussion of future possible extensions follow. 


\section{Occasional Interventions and the Behavior of Rates}

Participants in some asset markets hold large enough inventories that they may temporarfly affect the asset price when they trade. Therefore, the current asset price reflects the anticipation of these trades by the market as a whole. Examples include gold price dependence upon official holdings of gold reserves, stock price sensitivity to portfolio insurers and other large traders, as well as expectations of managed float interventions to target interest rates and exchange rates. ${ }^{6}$ The analysis below demonstrates how general forward-looking asset prices will reflect anticipations of the behavior of large traders such as central banks. Despite its general representation, however, the asset price variable will be called the "exchange rate" since the analysis will be applied to the foreign exchange market below. Before developing the general analysis, however, the behavior of the large traders will first be motivated with evidence from G-3 foreign exchange intervention policy.

A. G-3 Intervention Policy and Exchange Races: The Evidence

In 1985, the U.S. resumed foreign exchange intervention after a hiatus during the period of the first Reagan administration. The decision to intervene followed a period of persistent appreciation of the dollar that was perceived as damaging the demand for U.S. exportable goods. Following a meeting of the G-5 countries in January of 1985 and later at the "Plaza Meeting" in September that year, the governments announced that they considered desirable a fall in the value of the dollar. Subsequently, the dollar declined dramatically against both the Deutschemark and the Japanese yen. By February, 1987, depressed demand

${ }^{6}$ For example, Salant and Henderson (1978) demonstrate how the price of gold reflects the market's expectation that governments might unload their reserves of gold. 
upon Japanese and German goods due to the weakness of the dollar led to the "Louvre accord," an agreement to stabilize exchange rates by the central banks." Funabashi (1989) and Dominguez (1989) glve the target levels following the Louvre as 153.5 yen/dollar and $1.825 \mathrm{dm} /$ dollar. According to these sources, the yen/dollar target was later rebased to 146 yen/dollar. During the months following the Louvre accord, exchange rates appeared stable relative to the previous two years. Therefore, this stability was considered by some market observers as evidence that central bank intervention had been successful.

To investigate the relationship between exchange rates and intervention over the periods from the Plaza to the post-Louvre, exchange rate series were combined with a series for days when G-3 central banks were observed by traders to be intervening. The intervention series were compiled from daily newspaper accounts from the New York Times, Wall Street Joumal, and the London Financial Times. 8 Dumy variables were constructed for days when the market observed the G-3 central banks intervening. The daily exchange rate data from the International Monetary Fund were kindly provided by Kathryn Dominguez.

Table 1 describes summary statistics of interventions by the Federal Reserve, the Bundesbank, and the Bank of Japan over the full period and subsamples of intervention episodes. Intervention accounts were also broken down into dollar sales (to weaken the dollar) and dollar purchases (to support the dollar). The data series point out at least three interesting features of the

${ }^{7}$ Dominguez (1989) describes the various episodes of intervention from the Plaza meeting in September 1985, to the Tokyo meeting in May 1986, and the Lourre in February 1987.

${ }^{8}$ Dominguez (1989) uses confidential intervention data from the Federal Reserve and the Bundesbank and finds that newspaper accounts were generally accurate in observing foreign exchange interventions over the period. 
interventions. First, central bank intervention occured frequently during the period. For the full sample, central bank intervention by at least one of the three central banks (1isted under "Combined") occured 30.48 of the total days. Second, central banks intervened around a much tighter $r$ ange of the exchange rate following the Louvre than previous periods. For example, from the plaza to the Louvre, the difference between the average DM/dollar rates where the Fed intervened to sell and purchase do1lars was DM .6 (2.67 - 2.17) while following the Louvre it was DM .06 (1.87-1.81). Third, intervention occured at various different levels of the exchange rates even for the period following the Louvre accord. Thus, the joint pattern of intervention and exchange rates suggests that greater exchange rate stabilization coincided with more active intervention.

The pattern appears somewhat perplexing in light of evidence concerning foreign exchange intervention, however. The G-3 central banks conduct foreign exchange policy so that at least some of the intervention's effects upon the domestic money supply are sterilized. ${ }^{9}$ But empirical studies have found little evidence of a portfolio balance channel that would provide a rationale for effective sterilized intervention policy. 10

On the other hand, the evidence in Table 1 indicates that central banks were visible and active participants in foreign exchange markets over the period. And in contrast to private market participants, demand and supply of foreign exchange by these central banks depend upon exchange rate policy motives. Thus, if private agents feel uncertain about how much of the intervention will be

${ }^{9}$ The Federal Reserve automatically sterilizes foreign exchange interventions while the Bundesbank and the Bank of Japan implicitly sterlize at least partially through domestic monetary targets.

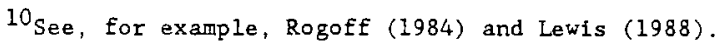


sterlized or if Interventions are sterilized with some delay, these interventions can induce intradaily capital gains or losses to private market traders. 11 In either case, anticipations of these occasional discrete events would therefore influence the short run behavior of the exchange rate.

To consider more generally the effects upon asset prices of occasional large trades, the following section develops a model of discrete stochastic "Interventions" in the context of the standard forward-looking asset price model. For comparison, the section also develops the "target zone" model recently developed by Krugman (1990) and Froot and Obstfeld (1989). For the case of forelgn exchange intervention, the evidence in Table 1 is shown to contrast sharply with this target zone model.

It should be emphasized at the outset that the purpose of the following application to foreign exchange is positive and not normative. We will ask how the short run behavior of the exchange rate would be influenced by central bank intervention policy that appears consistent with the evidence in Table 1 . This analysis should not be construed as indicating the appropriateness of this policy, however. 12

B. The Behavior of Rates with Discrete Stochastic Intervention Policy According to the standard asset pricing relationship, these prices depend upon a set of fundamental variables that influence the demand for and supply of

${ }^{11}$ These two possibilities have very different longer term effects upon the exchange rate. If all intervention is sterilized with a delay, the exchange rate is only temporarlly affected. On the other hand, if some intervention is allowed to be monetized, the exchange rate will be affected through the standard monetary channe1.

12 For example, Flood and Garber (1989) show that stabilizing the exchange rate using intervention policy implied by a target zone model increases the variance of interest rates. 
the asset at each point in time and upon the expected future asset price. In general, the relationship between the asset price and its fundamentals is given by:

(1) $s(t)=n(t)+\alpha E(d s(t)) / d t$

where $s$ is the logarithm of the asset price, $n$ is its "fundamental", and a parameterizes the sensitivity of the asset price to its own expected future change. This equation represent in general the behavior of prices that have forward-looking solutions such as stock prices (Shiller (1981)), gold prices (Salant and Henderson (1978)), long bond rates (Shiller (1979), and hyperinflations (Sargent and wallace (1973), Flood and Garber (1980)). Since the analysis will be empirically applied to foreign exchange below, this asset price will be called the "exchange rate" for the remainder of the paper. 13 In this context, the behavior of occasional discrete trades will take a form consistent with foreign exchange intervention policy, although generalizations of these events will be discussed below.

By solving (1) forward, the basic solution to the exchange rate is given by:

(2) $s\left(t_{0}\right)-(1 / \alpha) \int^{\infty} e^{\left(t_{0}-t\right) / \alpha} E\left(n(t) \mid \Omega\left(t_{0}\right)\right) d t$

${ }^{13}$ In general, $n(t)$ may be regarded as the combination of factors that determine the flow supply relative to demand for foreign exchange. See, for example, Mussa (1982) and Frenkel and Mussa (1980). In a monetary model, $n(t)$ is excess flow domestic money demand and $\alpha$ is the semi-elasticity of money demand. 
where $\Omega_{t}$ is the information set at time that includes any possible discrete events such as intervention. To find the solution to eqn. (2) we need to know the law of motion of fundamentals. A convenient law of motion that has been studied in the literature is: 14

(3) $\mathrm{dn}-\mu \mathrm{d} t+\sigma \mathrm{dz}$

where $\beta$ is the drift in $n(t)$ and $d z$ is the increment of the standard Weiner process.

In the absence of discrete interventions (and with no bubbles), the exchange rate solution depends linearly upon these fundamentals:

(4) $s(t)-n(t)+\alpha \mu$

That is, the exchange rate depends upon current fundamentals, $n(t)$, and the discounted expected future fundamentals, $\alpha \beta$.

On the other hand, when the market anticipates that central banks might intervene, this intervention will alter the market's expectations of future supply and demand for forelgn exchange. These anticipations, captured by $\Omega$, influence the relationship between the exchange rate and fundamentals. To demonstrate how anticipations of discrete interventions would affect the exchange rate in this framework, we will first consider the target zone model developed by Krugman (1990) and Froot and Obstfeld (1989) to provide a comparison.

(B. i) The "Target Zone" Model

When market traders know that the authorities will keep the exchange rate within certain bands, this knowledge affects the boundary conditions for solving

${ }^{14}$ Krugman (forthcoming) considers the case where $\beta=0$. More complicated processes have also been analyzed within this framework. For example, Froot and Obstfeld (forthcoming) solve for the form of the exchange rate for a process with mean-reversion in fundamentals. 
eqn. (2). For comparison with the stochastic intervention model below, the intervention strategy considered here will follow the policy discussed by Froot and Obstfeld (1989).15 Specifically, suppose that the authorlties announce a policy to intervene whenever the exchange rate reaches an upper limit, $s_{1}\left(\Omega_{1}\right)$, or a lower limit, $s_{1}\left(n_{1}\right)$. They achelve this objective by setting the change in the fundamental so that: $d n(t)=0$ when $n(t)=n_{2}$ or $n_{1}$. More formally, the fundamental process can be written as:

$$
d n-d f+d r
$$

$$
\text { where, } \begin{aligned}
& d f-\mu d t+\sigma d t \\
& d r=d L-d U .
\end{aligned}
$$

That is, df is the law of motion for the underlying fundamentals process given in (3), and $d r$ is a regulator of the fundamentals process comprised of a lower (dI) and upper (dU) component. Specifically, when imposed this regulator offsets the flow change in the fundamentals and is given by: 16

$$
\begin{array}{ll}
d r=-d U, & \text { if } n=n_{u} \\
d r=d L, & \text { if } n=n_{1} \\
d r=0, & \text { otherwise. }
\end{array}
$$

Using Ito's Lemma, the solution to eqn. (2) is given by the differential equation in $\mathrm{n}$ :

(6) $S(n)=n+\alpha \mu S^{\prime}(n)+(1 / 2) \alpha \sigma^{2} S^{\prime}(n)$

Solving for the differential equation in terms of the boundary values of $n$ given by (5) yields the relationship between fundamentals and the exchange rate

${ }^{15}$ other regimes and intervention policies can also be considered in the framework. See Froot and Obstfeld (forthcoming, 1989) and Flood and Garber (1989).

${ }^{16}$ For a discussion of regulated Brownian motion, see Harrison (1985) or Karatzas and Shreve (1988). 
described in the hatched curve in Figure 1.17 As fundamentals approach the intervention points for fundamentals (here $n_{1}, n_{n}=+1-1.775$ ), market traders recognize that the exchange rate will be stopped from exceeding the limits of the band. The expectation of no depreciation of the exchange rate at $s_{u}$ makes foreign exchange traders bid up the value of the currency at every lower value of fundamentals. Therefore, the exchange rate function bends away from this intervention point and lies everywhere below the free float solution.

The boundary condition is clearly a key assumption in the target zone analysis. Market traders must know with certainty both that intervention will take place at the boundary points and also the size of the intervention. 18 Furthermore, interventions occur only at the boundaries while the fundamentals are allowed to move freely when the exchange rate is within the band. But the evidence in Table 1 invalidates these assumptions for recent managed float experience. Specifically, interventions have taken place at various exchange rate levels and have not occured with certainty at any single exchange rate.

Furthermore, large discrete trades that may appear in other markets such as equity are also uncertain events. Therefore, the following model incorporates this behavior and lays the groundwork for the empirical implementation below. (Bii) The Behavior of Rates Amid Stochastic Intervention Policy

In order to represent uncertain large trades such as in the managed float

${ }^{17}$ The differential equation in (6) can be solved as an ordinary second order differential equation using the regulator in (5) to impose the boundary conditions. See, for example, Froot and Obstfeld (1989) or Svensson (1989). This solution is not presented in the text since this model is not the primary focus of the paper.

${ }^{18}$ Flood and Garber (1989) consider intervention policles where the size of interventions are discrete and known. On the othẹ hand, Miller and Weller (1989), Svensson (1989) and Bertola and Caballero (1989) consider expectations of uncertain discrete devaluations. 
experience, we must allow the market to assess the probability of intervention at any given rate. Although the market perceives intervention as uncertain, the central bank may make decisions deterministically, for example, as a function of other random target variables that private traders do not observe. Thus, the framework to be developed below requires only that the market cannot perfectly predict whether intervention will occur at any given exchange rate. Since the exchange rate depends upon fundamentals, the probability of intervention may be treated as a function of fundamentals. ${ }^{19}$ For expositional simplicity, we will consider one-sided intervention policy while developing the model.

To consider the effects of stochastic intervention, we require a forecast of intervention at every level of fundamentals. In this regard, the probability of intervention seems likely to increase as fundamentals deviate from the level that yields the target exchange rate. Therefore, if the target level of the exchange rate is $S\left(n_{0}\right)$, the probability of intervention should increase the farther is $n$, the current fundamental, from $n_{0}$.

The market views central bankers as traders in the market who may periodically intervene in large quantities. Since data on actual intervention amounts are not publicly available, we will treat the interventions as momentarily absorbing the excess demand/supply in the foreign exchange market and therefore stopping the exchange rate. Specifically, at any moment, they set: $d n-0$ with probability $\pi\left(n-n_{0}\right)$, or $d n=\mu d t+\sigma d z$ with probability (1 $\left.-\pi\left(n-n_{0}\right)\right)$. More formally, as $i n(5)$, the fundamentals variable is the sum of the underlying process and the regulator: $d n=d f+d r$, where $d r=d L-d U$

${ }^{19}$ Froot and obstfeld (forthcoming, 1989) discuss the problem of multiple equilibria in this class of models. In general, unless the market knows the intervention policy of the central bankers for given values of fundamentals, there will be multiple equilibria, 
and df follows the same process as in (3). However, the process for the regulator is now given by:

$$
\begin{aligned}
& d r=-d U, \\
& d r=d r \\
& d r=0,
\end{aligned}
$$

with probability $\pi_{\mathrm{u}}\left(n-n_{0}\right)$ when $n>n_{0}$ with probability $\pi_{1}\left(n-n_{0}\right)$ when $n<n_{0}$.

otherwise

where $\pi_{u}, \pi_{1}$ are probabilities of the upper and lower regulators, respectively. It will prove convenient below to set $n_{0}$ equal to zero, treat this probability as symmetric, and discuss the upper-level intervention policy where the probability of intervention $i s \pi(n)$ and $\pi^{\prime}(n)>0$. All of the following analysis can easily be extended to the two-sided intervention case by specifying the probability of intervention in terms of the distance of fundamentals from a midpoint target level. 20

The equilibration of the market with this intervention policy may be understood as follows. Within any small interval of time, $r$, a realization of the excess supply/demand for foreign exchange occurs. Since central banks are also trading in the market, they view the direction of flow demand $\left(\operatorname{dn}\left(t^{+}\right)\right)$and decide to intervene or not based upon seeing where fundamentals are going. Finally, given the actions by both the private agents and the central bank, the market clears. This type of intervention policy incorporates the realistic feature that the central banks are active participants in the market. 21

${ }^{20}$ The appendix describes the solution when the target level of the exchange rate corresponds to the value of $n_{0}-0$. In this case, we can specify the twosided probability of intervention to depend upon the square of fundamentals: $\pi\left(\mathrm{n}^{2}\right)$.

${ }^{21}$ In the language of stochastic calculus, this is a "reflecting barrier" that occurs stochastically where the probability of regulation is a function of the level of the regulated process. See the appendix for details. 
For the intervention policy in (7), the appendix shows that the equilibrium exchange rate solves the differential equation:

(8) $S(n)=n+\alpha\left[(1-\pi(n)) \mu-\pi^{\prime}(n) \sigma^{2}\right] S^{\prime}(n)+(1 / 2) \alpha \sigma^{2}(1-\pi(n)) S^{\prime}(n)$ Comparing this solution to the "target zone" solution in eqn. (6) illustrates the distinction between the two equations. When Intervention is stochastic, the expected future values of the fundamentals are weighted by the probability of no intervention at that point. Thus, in contrast to eqn. (6), the probability of no intervention, $(1 \cdot \pi)$, multiplies both the drift term, $\mu$, and the variance term, $\sigma$, in eqn. (8). Furthermore, this equation also contains an additional term, - $\pi^{\prime}(n) a^{2} S^{\prime}(n)$. This term captures the effects due to intervention instantaneously stopping the motion of fundamentals, and therefore, the exchange rate. That is, an increase in fundamentals pushes up the probability that intervention will occur and therefore reduces the expected change in the exchange rate.

To examine the relationship between occasional interventions and capital losses on foreign exchange holdings, consider the behavior of the exchange rate when intervention occurs. Within any time interval, the exchange rate will change according to: $d S(n)-\mu d t+\sigma d z$, if no intervention or

$$
d S(n)=0, \quad \text { if intervention occurs. }
$$

Clearly, when intervention occurs, traders holding foreign exchange will experience capttal losses relative to the interest differential.

With uncertainty about Intervention as in equation ( 8 ), the exchange rate must solve a partial differential equation in $S(n)$ and the probability distribution function $\pi(n)$. Given a probability distribution function of 
intervention, this equation can be solved numerically. ${ }^{22}$ Moreover, the choice of distributions critically affects the relationship between fundamentals and the exchange rate. In particular, how quickly the probability increases as fundamentals deviate from their target levels determines the sensitivity of market expectations about interventions. To fix ideas, we may define the probability of intervention in terms of a general cumulative distribution function, $F(\cdot)$, together with two parameters, $b$ and $\delta$. Specifically, define $b$ as the elasticity with respect to fundamentals of the odds for intervention relative to no intervention; $1 . e ., b=d \log (\pi /(1-\pi)) / d n$. Furthermore, let $\delta$ define a truncation point in the cumulative distribution function to insure that the probability range includes one. Put together, the probability function may be described as: $\pi(n ; b, \delta)-F(n ; b)$ for $F \leq \delta$,

$$
\text { - } 1 \text { otherwise. }
$$

That is, when the function $F$ is less than the truncation point, $\delta$, the elasticity of the odds ratio equals $b$. However, when $F$ exceeds this point, the probability equals one. ${ }^{23}$

Given a probability function together with values for $\alpha, \mu$, and $\sigma$, we may solve for the exchange rate up to two arbitrary conditions. As a first condition, the exchange rate was set equal to zero when fundamentals were zero. Figure 2 describes the family of solutions for this initial condition for arbitrary second conditions. The paths labeled $S_{A}$ and $S_{B}$ describe explosive

${ }^{22}$ For continuous functions of $\pi(n)$, the differential equation ( 8 ) has a solution in the class of confluent hypergeometric functions. See Froot and obstfeld (forthcoming).

${ }^{23}$ The truncation point is assumed to allow more generally for distribution functions that approach one only asymptotically. Of course, for any distribution function with finite supports, the truncation points are already implied. A uniform distribution provides an immediate example. 
paths for the exchange rate. However, there are a family of solutions that look like the paths labeled $S_{B}$ and $S_{S}$ that increase over a range of the fundamentals, but then decline.

To find the "saddle path" exchange rate solution from this family of solutions, we can use an economic argument. Specifically, as fundamentals increase and push the exchange rate away from the central bank's target exchange rate level, the probability of intervention approaches one. At the point where the probability equals one, market participants know that intervention will occur should the exchange rate ever reach this level. At this point, labeled $\bar{n}$ in Figure 2, the change in the exchange rate must be zero so that $S^{\prime}(n)-0$. This "smooth pasting" condition picks out $S_{S}$ as the exchange rate solution. ${ }^{24}$

The location of this boundary around the exchange rate depends upon the sensitivity of the intervention probability to changes in fundamentals as measured by the parameter, b. Intuitively, when the probability converges relatively slowly to one, then the implicit boundary around the exchange rate is wide relative to a probability that converges more quickly. To see why, note from the definition of the intervention probability that $\pi\left(n ; b^{H}, \delta\right)>\pi\left(n ; b^{L}, \delta\right)$ for $b^{\mathrm{H}}>b^{\mathrm{L}}$ at any given level of the fundamental $n$. Therefore, as shown in Figure 3, the maximum point of the solution occurs at a lower level of the fundamental for the probability distribution with a relatively high $b$. Intuitively, a tighter probability distribution of intervention (i.e., higher b) implies a tighter implicit boundary around the exchange rate.

Using particular values for the parameters $b, \delta, \sigma$, and $\mu$, we may solve for the exchange rate relation ( 8 ). The solid line in Figure 1 depicts the

${ }^{24}$ On the "smooth pasting" condition and the related "value matching" condition, see Dixit (1989) and Dumas (1989). 
exchange rate solution when $\mathrm{b}-1$ and $\delta=.95 .^{25}$ The exchange rate was solved using the values of the parameters from froot and obstfeld (1989) for $\alpha$ and $\sigma$ where the drift term, $\mu$, was equal to 0 , although a similar picture obtains for non-zero drift. To allow for a two-sided intervention policy, the probability of intervention was assumed to be symmetric around $n_{0}=0$, and for simplicity, was specified as quadratic in $n: \pi\left(n^{2}\right)$.

As the figure shows, the solution has the same basic shape as the target zone solution (in triangles). But since the market anticipates intervention within the boundaries, the implicit zone solution lies everywhere interior to the target zone solution and with flatter slope. Intuitively, as fundamentals increase from the target level and the probability of intervention increases, traders consider capital losses on foreign exchange holdings more likely. Therefore, they bid up the value of the domestic currency relative to a target zone with identical boundaries.

Although the theoretical relationship between the exchange rate and fundamentals with the implicit zone looks similar to a target zone, the distributions of fundamentals and therefore rates are very different. In the target zone model, fundamentals are uniformly distributed. The bottom of figure 4 gives a histogram of 1000 observations of this process. By contrast, the top panels show histograms of fundamentals with stochastic intervention for successively tighter probability distributions. Here, observations of fundamentals cluster near the center of the band. Taking these histograms

${ }^{25}$ To calculate this particular figure, the distribution function was assumed to be $\log i s t i c$ so that for $F()<\delta-.95, \pi=[\exp (a+b n) /(1+\exp (a+b n))]$. the elasticity of the odds ratio, $b$, was set equal to one, and $a--3$. However, this general shape holds both for other parameter values of $\delta, a$, and $b$, and for other distribution functions such as the normal distribution. 
rogether with Figure 1 demonstrates that the corresponding exchange rates are also concentrated near the center of the band (these exchange rate histograms are not shown due to space constraints). By contrast, exchange rates observations in the target zone model are minimized at the target level and concentrated near the boundaries.

In principle, fundamentals will evencually reach any given boundary with a sufficiently large number of observations. However, the number of periods the process requires to hit such a boundary depends upon how quickly the probability of intervention approaches one. Intuitively, if the probability approaches one sufficiently quickly, the exchange rates will get stopped most of the time and will reach their boundaries only after an arbitrarily long time.

To consider this relationship, the process in equation ( 7 ) was simulated with different levels for $b$ and $\delta$. As noted above, the probability distribution determines the boundaries around the exchange rate. In order to compare distributions with the same boundaries, $\delta$ was allowed to vary so that, given different levels of $b$, the probability $\pi$ was set equal to 1 at the same level of fundamentals deviations. Table 2 reports the results of these simulations based upon the following steps. First, independent random sequences of the fundamentals process without intervention, in eqn. (3), were generated assuming the values for $\alpha$ and $\sigma$ in Froot and Obstfeld (1989) and assuming no drift, 1\%, and then $10 \%$ annualized drift, in turn. The number of periods for the process to hit the boundary was calculated for 250 sequences of the process. This procedure was repeated for 4 different values of percentage deviations in fundamentals from their target levels: $1 \%, 5 \%, 10 \%$, and 15\%. The first column reports the average number of years that would be required to hit the boundaries. As the numbers indicate, tighter bands generally imply shorter expected periods 
for the process to hit the boundary.

The next columns of the table report these same simulations for the process with intervention described in (7). These expected hitting times were calculated based upon different values of $b$, the elasticities of the probability odds. As these numbers suggest, the expected hitting times lengthen as the probability of intervention becomes more sensitive to deviations from the target. Intuitively, for higher $b$, the process gets stopped with greater frequency on the way to the boundary so that it takes much longer to get there. ${ }^{26}$

Overall, therefore, market anticlpations of more frequent interventions as rates deviate from the target level induce a nonlinear relationship between fundamentals and the rate. Depending upon the sensitivity of the intervention probability to deviations from target levels, these bands may in practice never by reached. The sensitivity of this probability is an empirical issue to which we now turn.

\section{Empirical Evidence on Intervention Policy and Targetting Rates}

Empirical estimation and implementation of target zone models are hampered by the lack of strong, systematic relationships between the exchange rate and variables typically considered to be fundamentals such as money, income, and prices. ${ }^{27}$ Furthermore, these data are not available at the same daily frequency as the intervention and exchange rate series. For these reasons, we will treat the identity of the fundamentals agnostically in the approach below. Instead,

${ }^{26}$ Indeed, for sufficiently high values of $b$ and boundary points, the number of periods required to hit the boundary were so large that the computer program could not converge.

27 For example, Meese and Rose (1990) use non-parametric estimation using data for fundamentals to detect non-linearities in the exchange rate as implied by the standard target zone model. However, they generally fail to find a significant relationship. 
we will take as given that the flow excess supply of foreign exchange follows the law of motion in (3). Given this relationship, the probability of intervention depends upon the empirically observed level of the exchange rate in equilibrium. To see this, recall that the equilibrium exchange rate that solves eqn. ( 8$)$ is $S(n)$ and that the probability of intervention depends upon fndamentals, $\pi(n)$. Therefore, in equilibrium,

(9) $\pi(n)=\pi\left(S^{-1}(n)\right)$.

This Implies an equilibrium relationship between the intervention probability in terms of fundamentals, on the one hand, and the intervention probability in terms of the exchange rate, on the other. In other words, we may define a probability of intervention in terms of the equilibrium exchange rate, $S^{*}=S(n)$, such that:

(10) $\pi\left(S^{-1}(\mathbf{n})\right)=\pi^{*}\left(S^{*}\right)$.

Therefore, using the exchange rate levels where intervention occured, the probability function $\pi^{*}\left(S^{*}\right)$ can be estimated empirically. We can then use empirical estimates of (10) together with a law of motion for fundamentals to infer the empirical shape of $S(n)$.

For this purpose, the following subsection provides empirical estimates of $\pi^{*}\left(S^{*}\right)$ from a multinomial logit model using the data on exchange rates and intervention described in Table 1. In subsection $B$, these estimated probability distributions are used to back out the implied relationship between the exchange rate and fundamentals.

\section{A. Estimating the Probability of Intervention}

The behavior of G-3 intervention policy appeared to change over the period from 1985 to 1987 as the dollar declined dramatically. In order to consider the behavior of intervention policy, the sample was divided into three different 
intervention subperiods described by Dominguez (1989). The first period begins with the Plaza meeting on September 23, 1985 and continues through to the Tokyo meeting on May 5, 1986. The second perfod lasts from the Tokyo meeting to the Louvre accord on February 22, 1987. As Table 1 shows, there was almost no intervention by the Federal Reserve during this time. Also, to the extent that the Fed and the Bank of Japan intervened, it was to support the weakening dollar. The third period follows the Louvre accord and will be the focus of the empirical simulation below. Durfing the perfod following the meeting on February 22, 1987 , the G- 3 central banks acted to stabflize exchange rates around particular target levels. The subsample terminates just before the U.S. stock market crash on October 19, 1987 since the Federal Reserve intervened to supply liquidity in response to this crists.

To characterize the probability of intervention, this probability was estimated as a multinomial logistic distribution for three possible intervention events on any given day, $t:^{28}$

$$
\begin{array}{ll}
I_{t}=0 & \text { for "No Intervention" } \\
I_{t}-1 & \text { for "Intervention to Weaken the Dollar" (dollar sales) } \\
I_{t}=-1 & \text { for "Intervention to Support the Dollar" (dollar purchases) }
\end{array}
$$

The probability of these events were estimated as functions of a constant and the level of the exchange rate corresponding to the close of the previous day, denoted $s_{t-1}$. With this distribution, the logarithrn of the odds ratios of dollar purchases to dollar sales and of no intervention to dollar sales are:

$$
\begin{aligned}
& \log \left(\operatorname{Prob}\left(I_{t}-1\right) / \operatorname{Prob}\left(I_{t}-1\right)\right)-c_{0}+c_{1} s_{t-1} \\
& \log \left(\operatorname{Prob}\left(I_{t}-0\right) / \operatorname{Prob}\left(I_{t}-1\right)\right)-g_{0}+g_{1} s_{t-1}
\end{aligned}
$$

${ }^{28}$ For detafls on the multinomial logit model, see Maddala (1986). 
where $c_{0}, c_{1}, g_{0}$, and $g_{1}$ are parameters to be estimated. These estimates are given in Table 3 for the yen and Table 4 for the DM. (Note that for these tables, $s_{t}$ is the price of dollars in terms of foreign currency.)

As both tables show, the model provides a fairly good fit for intervention from the Plaza-Tokyo (P-T) and the Louvre-Crash ( $L-C)$ periods, but not for the Tokyo-Louvre (T-I) period. Over the P-T and L-C periods, the coefficients for all of the central banks and the combined intervention equations are significant. Also, the coefficients on the exchange rate have the anticipated sign. Since $c_{1}<0$, an increase in $s_{t-1}$ (or a strengthening of the dollar) leads to a fall in the probability of dollar support relative to dollar weakening operations. Similarly, since $g_{1}<0$, a strengthening of the dollar leads to a fall in the odds of no intervention relative to intervention to weaken the dollar. In other words, the probability of intervention increases with movements of the exchange rate away from its target level. During the T-L period, the coefficients are insignificant in each equation except for the Bank of Japan, although they are of the expected sign in each equation.

The tables also report the probabilities of intervention at the mean exchange rate levels and, where applicable, the unofficial target levels reported by Dominguez (1989) and Funabashi (1989). These probabilities are calculated for the events of "intervention to support the dollar" (I - - I) and "no intervention" ( $I$ - 0). The residual, 1 - Prob(I - I) - Prob(I - O), equals the probability of "intervention to weaken the dollar" (I - 1).

For the post-Plaza period, the probability of no intervention ( $I=0$ ) tended to be much higher at the mean exchange rate level than at the Plaza meeting target exchange rate of $215 \mathrm{yen} /$ dollar and $2.55 \mathrm{DM} / \mathrm{dollar}$. This captures the feature that the probability of interventfon was higher immediately following 
the Plaza, while over time as the dollar weakened, the probability fell. Furthermore, the probability of interventions to weaken the dollar declines substantially over the period as well. As Table 3 shows, for example, the probability was 48 that the Bank of Japan would intervene to weaken the dollar when the exchange rate was at the Plaza target rate of 215 . But at the mean of 195.5, the probability of dollar-weakening operations ( $=1$ ) was essentially zero, while the probability of dollar-support interventions was about 18 .

For the Tokyo-Louvre period, the intervention estimates become very imprecise except for the Bank of Japan. These results appear reasonable, since there was much less intervention during this period. As Table 1 shows, the Federal Reserve intervened only an average of 13 of the days over the period.

Following the Louvre accord, intervention is again significantly related to the level of the exchange rate for all of the central banks. At the mean and target levels for both exchange rates, the probability of no intervention is very high. However, the probability of intervention to support the dollar is greater than the probability of weakening the dollar.

The estimates of the probability of intervention can also be used to calculate the target level of the exchange rate that the market would have inferred over the sample period. One way to calculate this target level is to find the exchange rate that sets the probability of intervention supporting the dollar equal to the probability of intervention weakening the dollar.

In terms of the model above, this corresponds to finding the exchange rate where $\log (\operatorname{Prob}(I--1) / \operatorname{Prob}(I-1))-0$, or where $s=-\left(c_{0} / c_{1}\right)$. Using this measure, the target levels implied by the model were very close to the actual target levels. For example, following the Louvre, the implied DM/dollar target rates was 1.85 DM compared to the actual target of 1.825 DM. And the implied 
yen/dollar target was 148 , between the initial Louvre target of 153.5 yen and the rebased post-Louvre target of 146 yen.

Overall, these results indicate that the estimated intervention model fits the episodes of intervention fairly well, partfcularly for the Louvre period. In the next period, the estimates for this period are used to solve backward to find the relationship between fundamentals and the exchange rate.

\section{B. Empirical Simulation of the Model}

Given the empirical probability function of intervention in terms of the exchange rate from above, i.e., $\pi^{\star}\left(\mathrm{S}^{\star}\right)$, we can now solve backward through (10) to find the equilibrium relationship between fundamentals and the exchange rate, $\pi\left(S^{-1}(n)\right)$. Through the exchange rate equation (8), this probability can then be combined with parameter values for $\alpha, \mu$, and $\sigma$, to solve for the equilibrium exchange rate. Specifically, rewriting the equation in terms of a given fundamentals value, $n_{i}$, and an arbitrary value of the probability, $\pi_{1}$, we have: (11) $\tilde{S}\left(n_{i}, \pi_{i}\right)-n_{i}+\alpha\left[\mu\left(1-\pi_{i}\right)-\sigma^{2} \pi_{i}^{\prime}\right] S^{\prime}\left(n_{1}\right)+\left(\alpha \sigma^{2} / 2\right)\left[1-\pi_{i}\right] S^{\prime}\left(n_{i}\right)$ But, in equilibrium, the intervention probabilfty depends upon this exchange rate:

(12) $\pi_{i}=\pi^{*}(S)=\pi^{*}\left(\tilde{S}\left(n_{i}, \pi_{i}\right)\right)$.

Therefore, for any given fundamental's level, $n_{i}$, we can solve the fixed point between the probability-to-exchange rate mapping in (11) and the exchange rateto-probability mapping in (12). We can then pick out equilibrium points in the exchange rate solution by incorporating the fact that the evolution of the exchange rate, the intervention probability, and the regulated fundamentals process all depend upon the same underlying stochastic process in equilibrium. 
Details of this inversion process is described in the appendix. ${ }^{29}$

The exchange rate solutions for the DM/dollar rate and the yen/dollar rate during the post-Louvre period were backed out from the multinomial logit probability estimates. ${ }^{30}$ The midpoints of the range were set at their Louvre target levels, while the empirical logit estimates determined the probability of intervention, $\pi^{\star}(S)$. In order to provide conservative estimates of the the extreme boundaries around the exchange rate, the distribution was truncated at levels of $\delta$ significantly below one. Specifically, the multinomial probability estimates using the exchange rate alone were bounded by $\pi=.5$. Therefore, $\delta$ was set equal to .5. The values in Froot and obstfeld (1989) of $\alpha-4$ and $\sigma$ - .1 were used to calibrate the parameters of the fundamentals process when no intervention occurs as defined in (3). Then, $\tilde{S}\left(n_{i}, \pi\left(\tilde{S}\left(n_{i}, \pi\right)\right.\right.$ was solved backwards using the iterative fixed point process described above.

Figures 5 and 6 illustrate these solutions for the post-Louvre period for the Dollar/Yen rate and the Dollar/DM rate, respectively. For each case, the solution was calculated from the target midpoint assuming both no drift (solid line) and 10 drift (cirled line) for the fundamental process. ${ }^{31}$ Greater drift implies that the expected value of fundamentals is higher in the neighborhood

${ }^{29}$ It is also straightforward to show existence of a solution for any value of $\mathrm{n}_{\mathrm{i}}$ using Brower's fixed point theorem.

${ }^{30}$ Since the model derived in Section I uses the logarithm of the exchange rate, the equations in Tables 3 and 4 were re-estimated using this form. The basic fit of the model remains the same as in these tables. Therefore, only the results using the level of the exchange rate are reported in the text for easy comparison with standard quotations of exchange rates.

${ }^{31}$ To retain symmetry in the $108 \mathrm{drift}$ case, the process was assumed to have positive drift when above the target level and negative drift when below the target level. If instead positive drift is as sumed throughout, the circled curve is steeper when below the target level although it retains the same general shape. 
of the target level, so that the 10 o drift solution lies above the no drift solution here. However, greater drift also increases the probability of intervention. Therefore, at higher deviations of fundamentals, the greater probability of intervention for positive drift makes the exchange rate solution fall below the "no drift" solution.

The figures also provide histograms of actual observations of the (logarithm of) exchange rates during the post-Louvre period. As these histograms indicate, the observed rates were concentrated far away from bands where the probability of intervention was even as low as .5 - - and even farther than bands with higher truncation probabilities. Therefore, this evidence suggests that rates were contained near the target zone with a relatively low likelihood of intervention around the target levels. For this policy to be work, however, the perceived threat of intervention must have increased with deviations from this carget level. The fact that these levels of the exchange rate were not observed lent credibility to the intervention policy.

As these results indicate, the exchange rates following the Louvre were bounded by the threat of intervention, a probability that was never much above 508. The intervention threat pushed the observations well within any implicit band of exchange rate levels where intervention would be certain. These results also suggest that the presence of theoretical non-linearities between the exchange rate and fundamentals near the boundary may not be empirically detectable. This part of the exchange rate-fundamentals relationship may simply be unobservable.

\section{Concluding Remarks and Extensions}

This paper has developed a model of asset price behavior when large traders such as central banks occasionally intervene and make prices change discretely. 
The paper analyzed the effects upon rates when central banks intervene to temporarily stop asset price movements away from target levels. The motivation was to considez the effects upon exchange rate behavior from implicit exchange rate targeting inherent in managed float policy. Clearly, the basic results apply to other financial variables such as interest rates that may be targeted by central banks in a similar managed float fashion. Furthermore, the analysis in the paper sets the foundation for considering the effects of discrete large trades upon other asset prices such as stock prices. With additional work, one may be able to characterize these trades in a similar manner to the discrete central bank behavior here.

For the application in the paper, the model delivers at least two important and interesting implications for exchange rate behavior. As the first implication, when private agents believe central banks will intervene more frequently as the exchange rate deviates from a target level, this belief implicitly bounds the exchange rate between rates of perceived certain intervention. Intuitively, intervention imposes capital gains or losses on holders of foreign exchange. Since the probability of capital losses on holdings of foreign exchange increases as the domestic currency weakens, say, anticipations of central bank intervention induce traders to hold more domestic currency than they would in a free float. Therefore, this threat of intervention induces exchange rates to rise less than proportionately to excess demand for foreign exchange. Making this threat credible leads to the second major implication of the model: exchange rate observations are concentrated near the target level and away from the implicit band. This implication arises since interventions that stop exchange rate movements occur with greater frequency as the exchange rate approaches the band. The model was calibrated using an 
estimated model of intervention policy following the Louvre accord period. Observations of the DM/dollar exchange rate were indeed concentrated near target levels and did not even approach the implicit boundaries.

This paper also provides the framework for considering a number of interesting related issues. First, in practice the exchange rate objectives of central banks may change over time, in contrast to the time-invariant intervention policy considered above. For example, the market may watch central bank actions to learn whether the intervention policy distribution changes over time. In this case, the market may "test" the willingness of central banks to intervene as exchange rates deviate from implicit targets. Speculation against the intervention policy may then force central banks to periodically intervene in order to restore confidence in this policy (e.g., to tighten the market's priors on the intervention distribution). 32

Second, despite the focus upon the managed float policy in this paper, the analysis may be applicable to features of fixed exchange rate arrangements such as within the European Monetary System. For Instance, central banks conduct intramarginal interventions within the band and one purpose may be to maintain credibility. If so, observations of exchange rates near the band would signal to private traders that the probability of intervention is lower than they had previously consldered. Therefore, these observations would lead the market to

${ }^{32}$ Evidence that the U.S. foreign exchange operations have followed this pattern is discussed in Humpage (1988). The effects of learning about intervention policy upon exchange rate behavior is the focus of klein and Lewis (in progress). In related issues, Flood and Garber (1980) study agents' beliefs about the credibility of government reforms using Bayesian methods, while Taylor (1975) examines the effects of systematic inflation surprises as the economy converges to equilibrium. 
believe a realignment may be forthcoming. 33

Third, this explanation suggests why central banks may prefer to conduct intervention randomly within the band. By fostering the belief that they will intervene randomly should the exchange rate deviate too much, central banks can obfuscate their true policy intentions while still exerting some influence upon short run exchange rate movements. By obfuscating policy, central banks may succeed in delaying speculative attacks that would be more immediate if, as in the standard assumption, a particular policy action at each level of the exchange rate were known with certainty.

As these examples demonstrate, the framework developed in this paper not only yields the interesting results presented in this paper, it can also incorporate a variety of interesting issues concerning variables that are targeted by managed float policy.

${ }^{33}$ Bertola and Caballero (1990) find that the behavior of exchange rates within the EMS is consistent with anticipations of realigments as exchange rates approach the bands. 
References

Bertola, Giuseppe, and Ricardo J. Caballero. "Target Zones and Realigrments." Columbia University Working Paper (December 1989).

Buiter, Willem H., and Vittorio U. Grilli. "The 'Gold Standard Paradox' and its Resolution." NBER Working Paper Series no. 3178 (November 1989).

Dixit, Avinash. "A Simplified Treatment of the Theory of Optimal Regulation of Brownian Motion." Princeton University Working Paper (October 1989).

Dominguez, Kathryn Mary. "Market Responses to Coordinated Central Bank Intervention." Camegie-Rochester Series on Public Policy 32 (Spring 1988).

Dumas, Bernard. "Super Contact and Related Optimality Conditions: A Supplement to Avinash Dixit's 'A Simplified Exposition of Some Results Concerning Regulated Brownian Motion'." NBER Technical Working Paper, no. 77 (April 1989).

Flood, Robert P., and Peter M. Garber. "The Linkage Between Speculative Attack and Target Zone Models of Exchange Rates." NBER Working Paper no. 2918 (April 1989).

Flood, Robert P., and Peter M. Garber, "An Economic Theory of Monetary Reform," Joumal of Political Economy, (February 1980) 88: 24-58.

Frenkel, Jacob A., and Mussa, Michael L., "The Efficiency of Foreign Exchange Markets and Measures of Turbulence," American Economic Review (May 1980) 70: $374-381$.

Froot, Kenneth A., and Maurice Obstfeld. "Exchange-Rate Dynamics under Stochastic Regime Shifts: A Unified Approach." Harvard Institute of Economic Research Discussion Paper no. 1451 (September 1989).

Froot, Kenneth A., and Maurice Obstfeld. "Stochastic Process Switching: Some 
Simple Solutions," Econometrica (forthcoming).

Funabashi, Yoichi. Managing the Dollar: From the Plaza to the Louvre, 2nd ed. (Institute for International Economics: Washington, D.C.) 1989.

Harrison, J. Michael, Brownian Motion and Stochastic Flow Systems. (John Wiley \& Sons: New York) 1985.

Heller, H. Robert, "Implementing Monetary Policy," Federal Reserve Bulletin, (July 1988) 74: 419-29.

Humpage, Owen F., "Intervention and the Dollar's Decline." Federal Reserve Bank of Cleveland Economic Review 24, no. 2 (1988): $2-16$.

Karatzas, Ioannis, and Steven E. Shreve. Brownian Motion and Stochastic Calculus. (Springer-Verlag: New York) 1988.

Klein, Michael W., "Big Effects of Small Interventions: The Informational Role of Intervention in Exchange Rate Policy." Clark University Working Paper (October 1989).

Klein, Michael W., "Playing with the Band: Dynamic Effects of Target Zones in an Open Economy." Intemational Economic Review (forthcoming).

Klein, Michael W., and Karen K. Lewis. "Learning about Foreign Excharge Intervention Policy." Working paper (in progress.)

Lewis, Karen K., "Testing the Portfolio Balance Model: A Multi-Lateral Approach," Joumal of Intemational Economics (February 1988),

Krugman, Paul. "Target Zones and Exchange Rate Dynamics," Quarterly Journal of Economics (forthcoming).

Krugman, Paul. "Target Zones with Limited Reserves." Working paper (August 1989).

Maddala, G.S. Limited Dependent and Qualitative Variables in Econometrics. (Cambridge University Press: Cambridge) 1983. 
Meese, Richard, and Andrew K. Rose, "Non-Linear, Non-Parametric, Non-Essential Exchange Rate Estimation." American Economic Review Papers and Proceedings $80($ May 1990)

Milier, Marcus, and Paul Weller, "Qualitative Solutions for stochastic Saddlepaths and the Analysis of Exchange Rate Regimes." Working paper (January 1989).

Mussa, Michael L., "A Model of Exchange Rate Dynamics," Joumal of Political Economy, (February 1982) 90: 74-104.

Rogoff, Kenneth, "On the Effects of Sterilized Intervention: An Analysis of Weekly Data," Joumal of Monetary Economics, (1984) 14: 133-50.

Salant, and Dale Henderson, "On Official Gold Holdings and the Price of Gold," Journal of Political Economy, (1978).

Sargent, Thomas J. and Neil Wallace, "Rational Expectations and the Dynanics of of Hyperinflation," International Economic Review, (June 1973) 14:328-50.

Shiller, Robert J., "Do Stock Prices Move Too Much to Be Justified by Subsequent Dividends?" American Economic Review, (June 1981) 71: 421-36.

Shiller, Robert J., "The Volatility of Long-Term Interest Rates and Expectations Models of the Term Structure," Journal of Political Economy, (December 1979): $1190-1219$.

Spencer, Michael G. "Nominal Exchange Rate Dynamics in the European Monetary System." Working Paper, Queen's University (January 1990).

Svensson, Lars E.O. "Target Zones and Interest Rate Variability." NBER Working Paper no. 3218 (December 1989).

Taylor, John B., "Monetary Policy During a Transition to Rational Expectations," Journal of Political Economy, (October 1975) 83: 1009-21. 


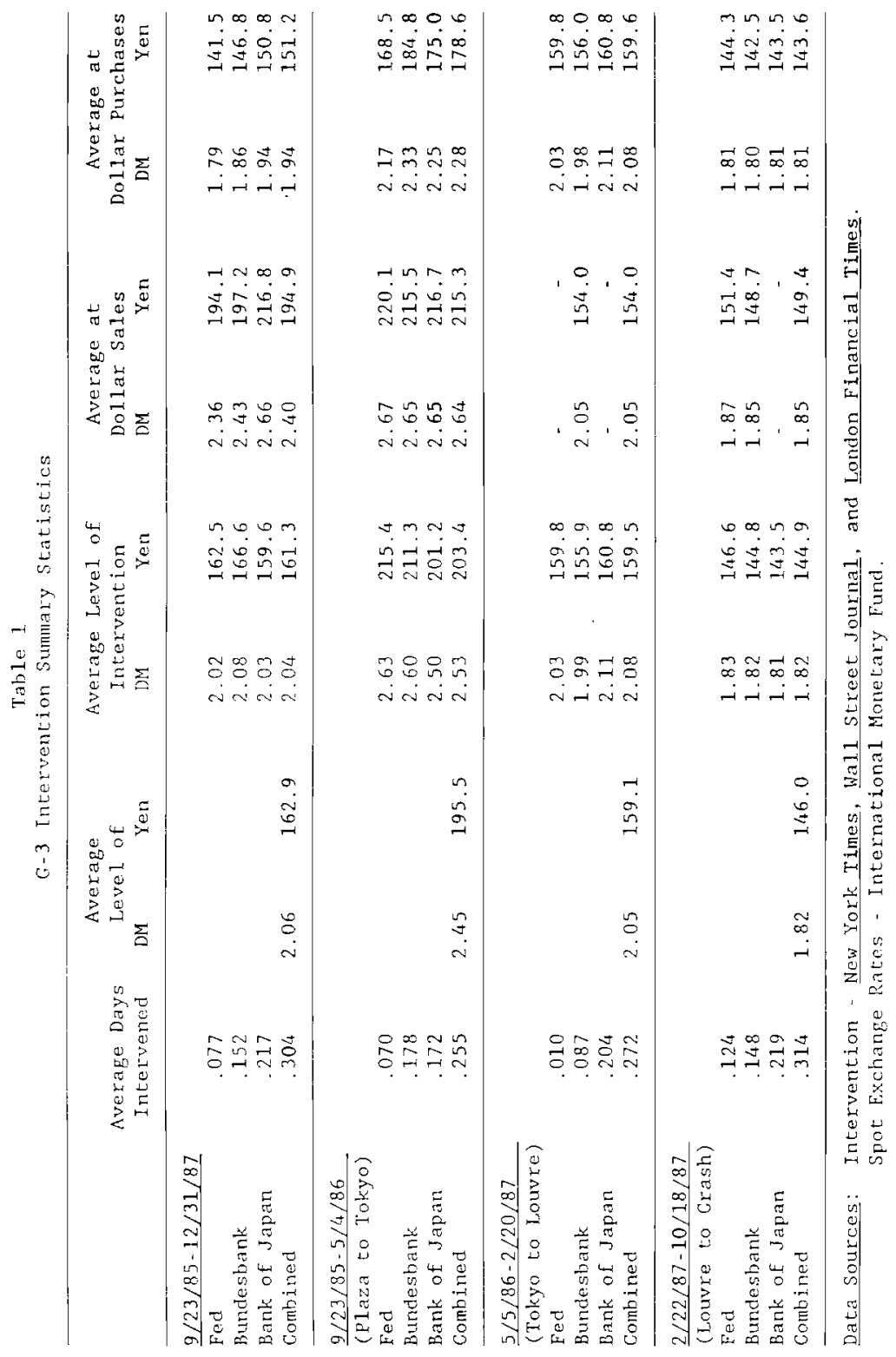


Table 2

First Boundary Hitting Tines

(Expected Values from Monte Carlo Simulations)

\begin{tabular}{llc}
\hline $\begin{array}{l}\text { Percent } \\
\text { Band of } \\
\text { Fundamentals }\end{array}$ & $\begin{array}{c}\text { Fundamentals } \\
\text { Without } \\
\text { Intervention }\end{array}$ & $\begin{array}{c}\text { Fundamentals } \\
\text { With } \\
\text { Intervention }\end{array}$ \\
& Elasticity of odds Ratio (b) & 1000 \\
\hline
\end{tabular}

Drift - 0 :

\begin{tabular}{|c|c|c|c|c|c|}
\hline 1 & 2.52 & 2.88 & 2.78 & 3.14 & 2.92 \\
\hline 5 & 31.87 & 32.98 & 35.20 & 36.91 & 55.75 \\
\hline 10 & 124.26 & 124.91 & 134.02 & 1361.74 & $-\ldots b$ \\
\hline 15 & 214.24 & 244.40 & 312.06 & $--^{b}$ & --- \\
\hline
\end{tabular}

Drift - 18 :

1

5

10

15
1.76

5.84

10.77

15.62
1.78

1.81

1.83

1.98

6.07

6.25

6.74

9.43

11.45

12.16

48.92

9694.18

17.02

19.22

24872.89

Notes: a based upon 100 replications. b process did not hit boundary after 1 milion periods.

Each mean based upon finding the number of periods before hitting the boundaries for 250 sequences starting at the midpoint. The primary fundamental process is: $n_{t}-n_{t-1}+\mu+\sigma^{2} L_{t}$ where $\sigma^{2}=.01$. "Without Intervention" reports average hitting times for this process. "With Intervention" gives the means for this process regulated with the probability: $\exp \left(b_{0}+b_{1} n^{2}\right) /\left[1+\exp \left(b_{0}+b_{1} \|^{7}\right)\right]$ where $b_{0}=-3$ in al1 cases. 


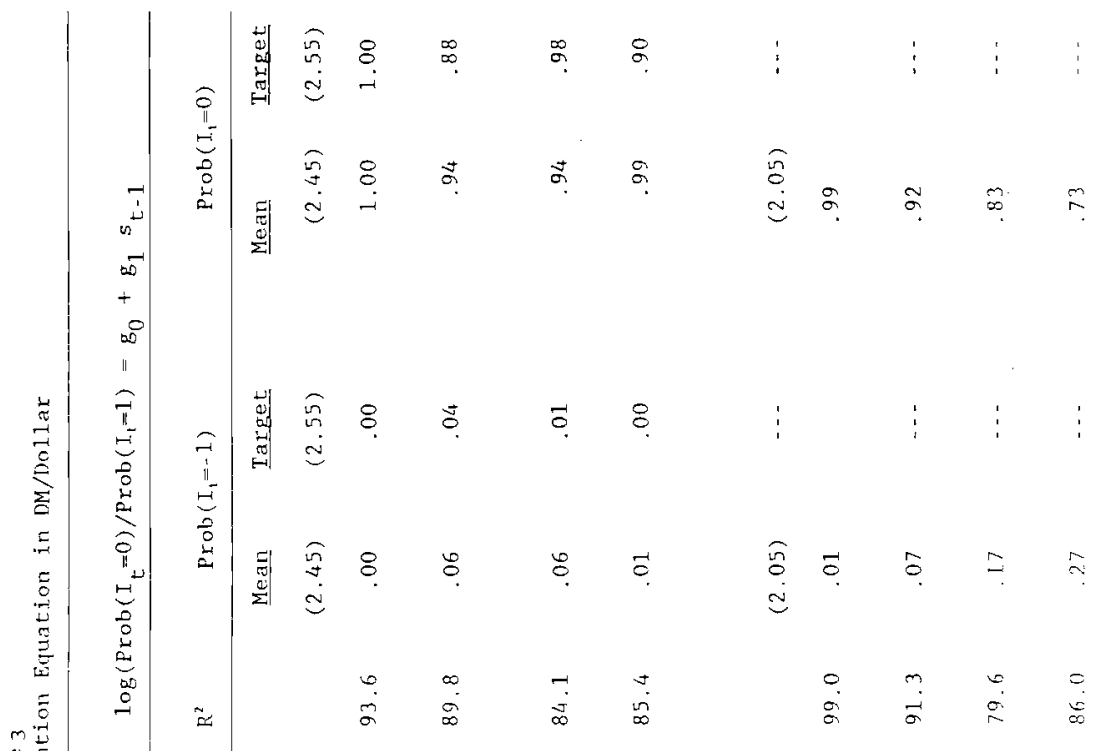

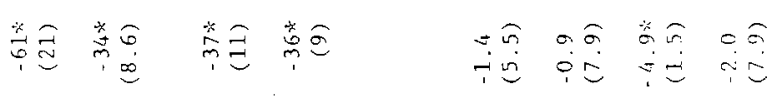

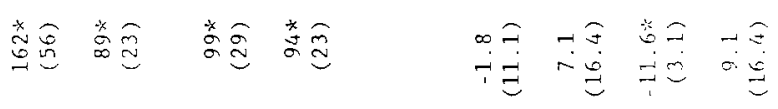

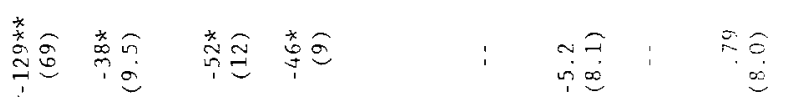

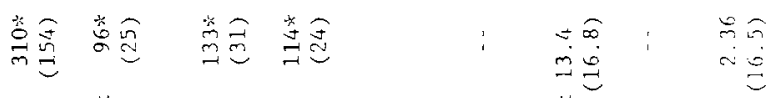

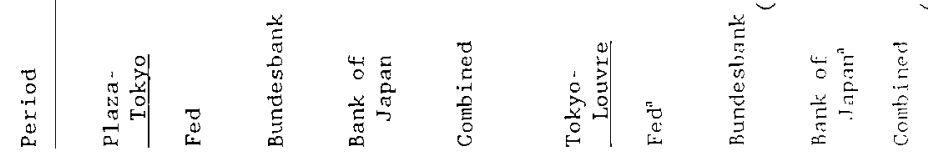




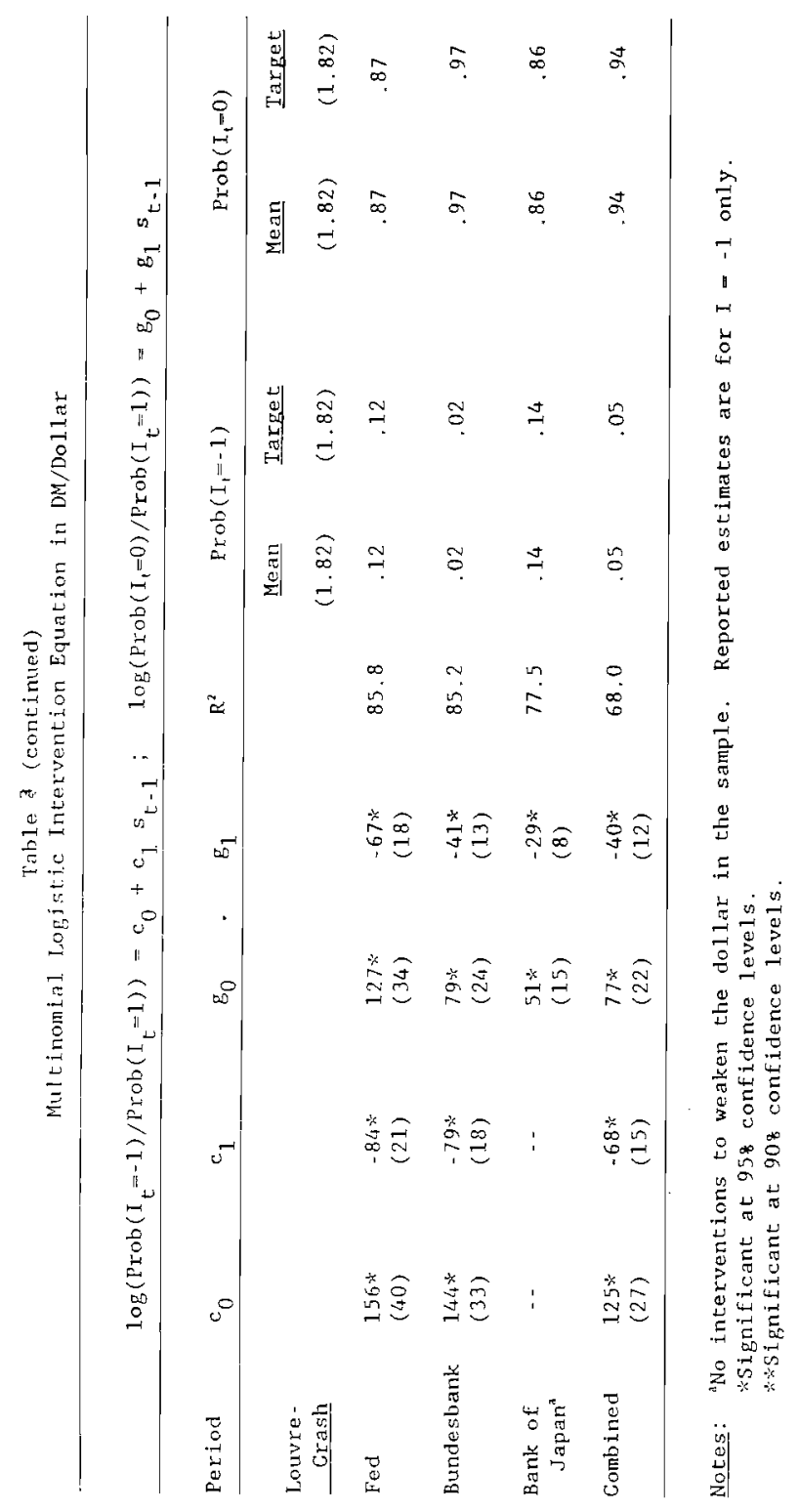




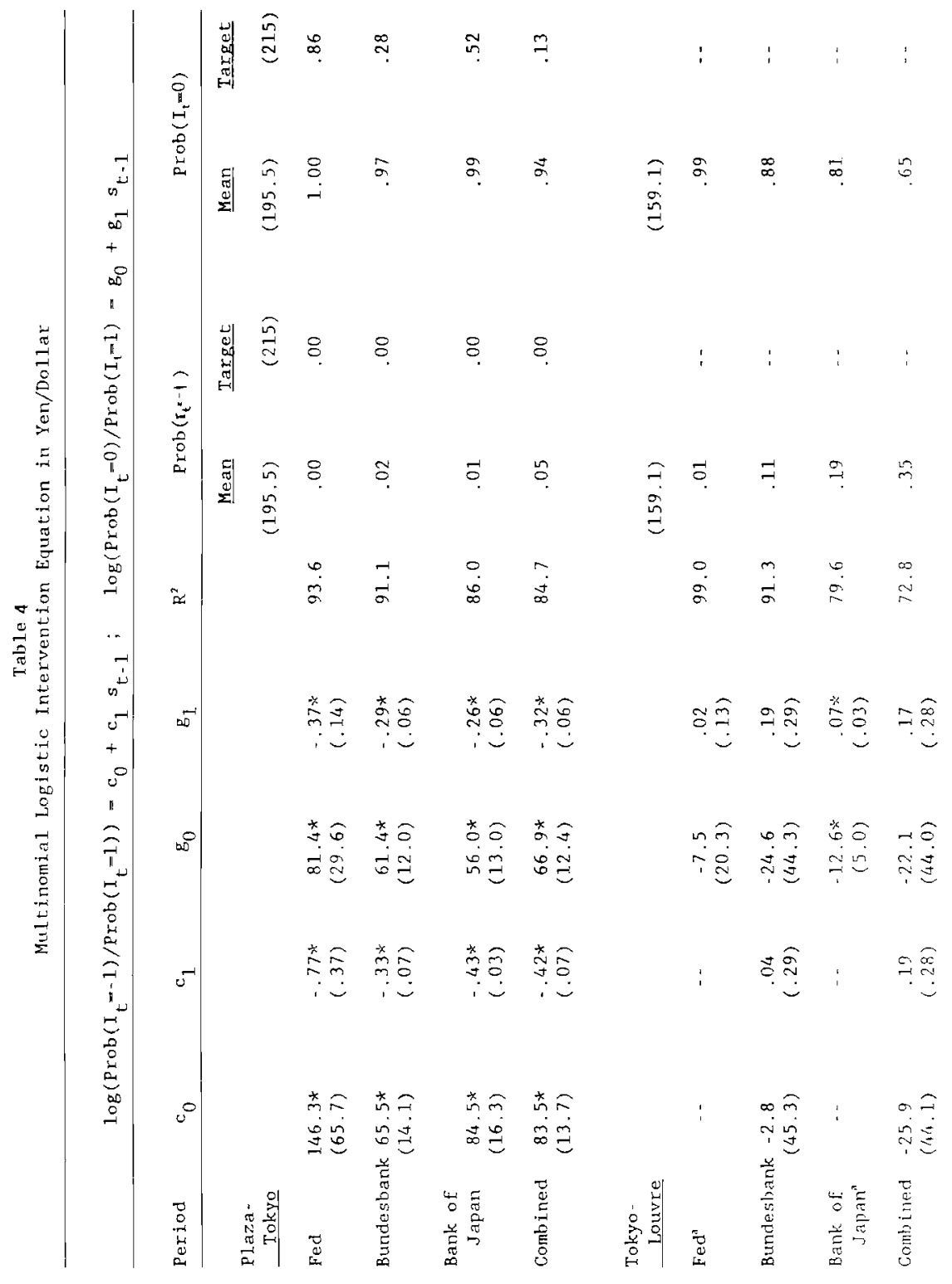




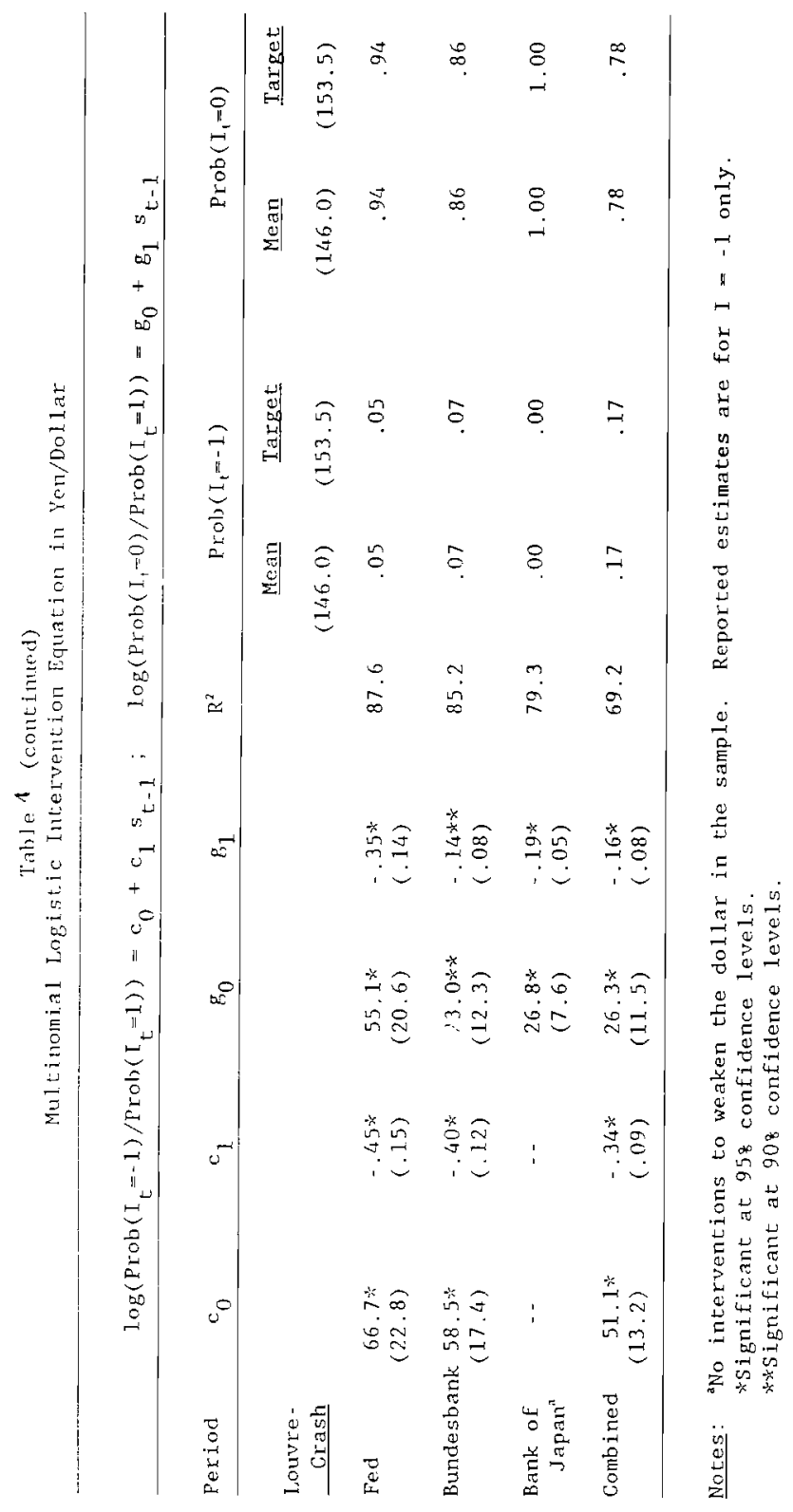




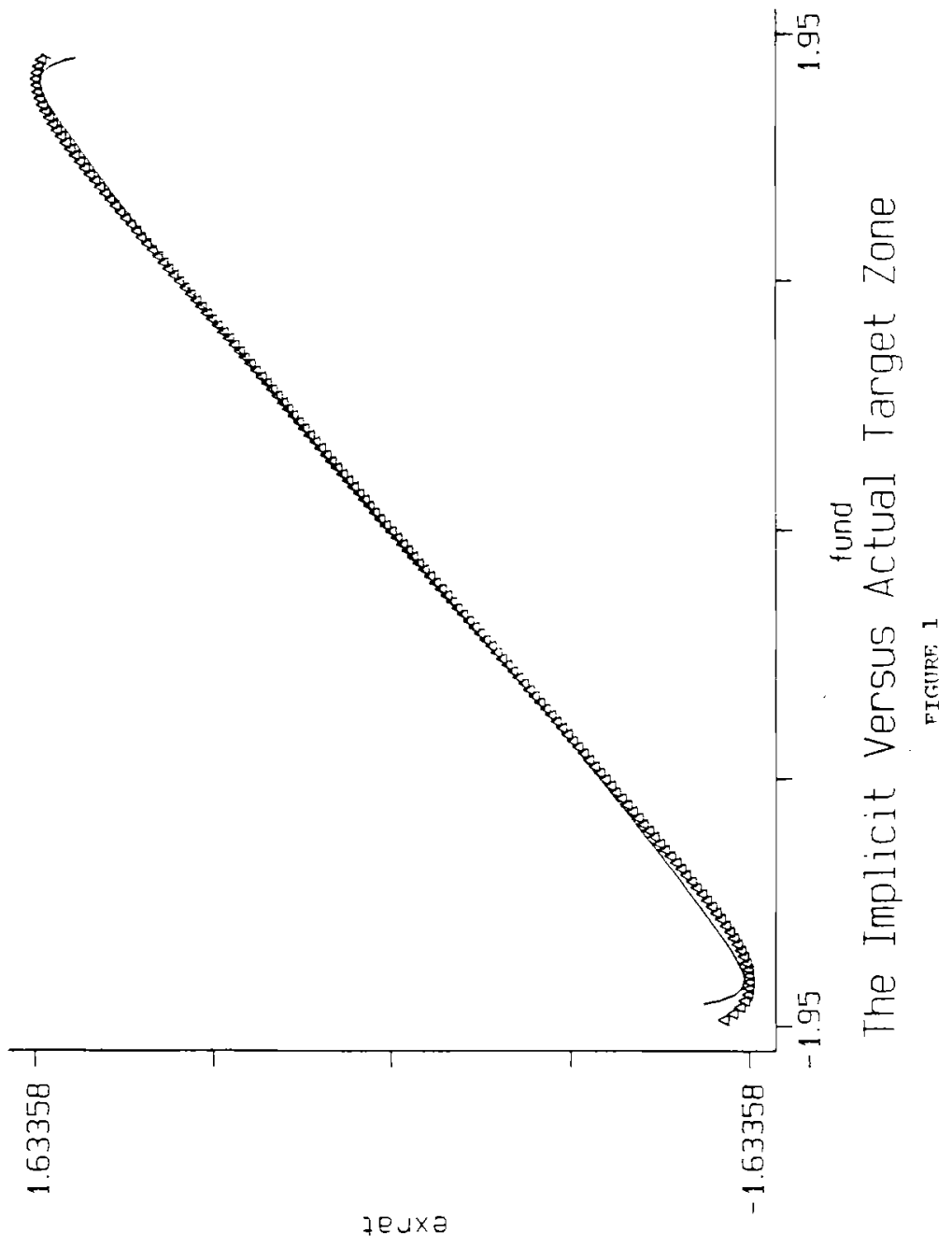




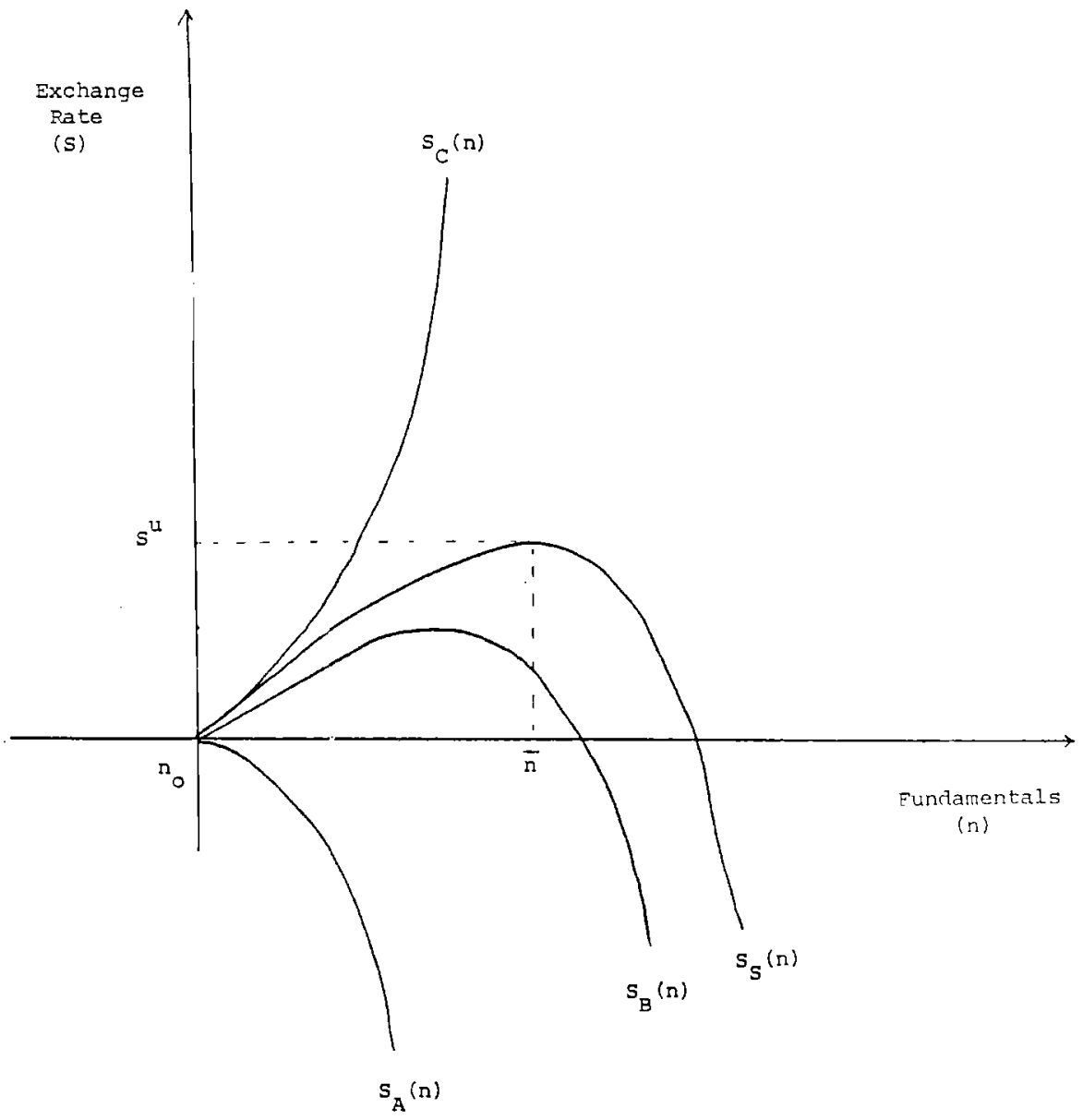

FIGURE 2: Exchange Rate Paths 


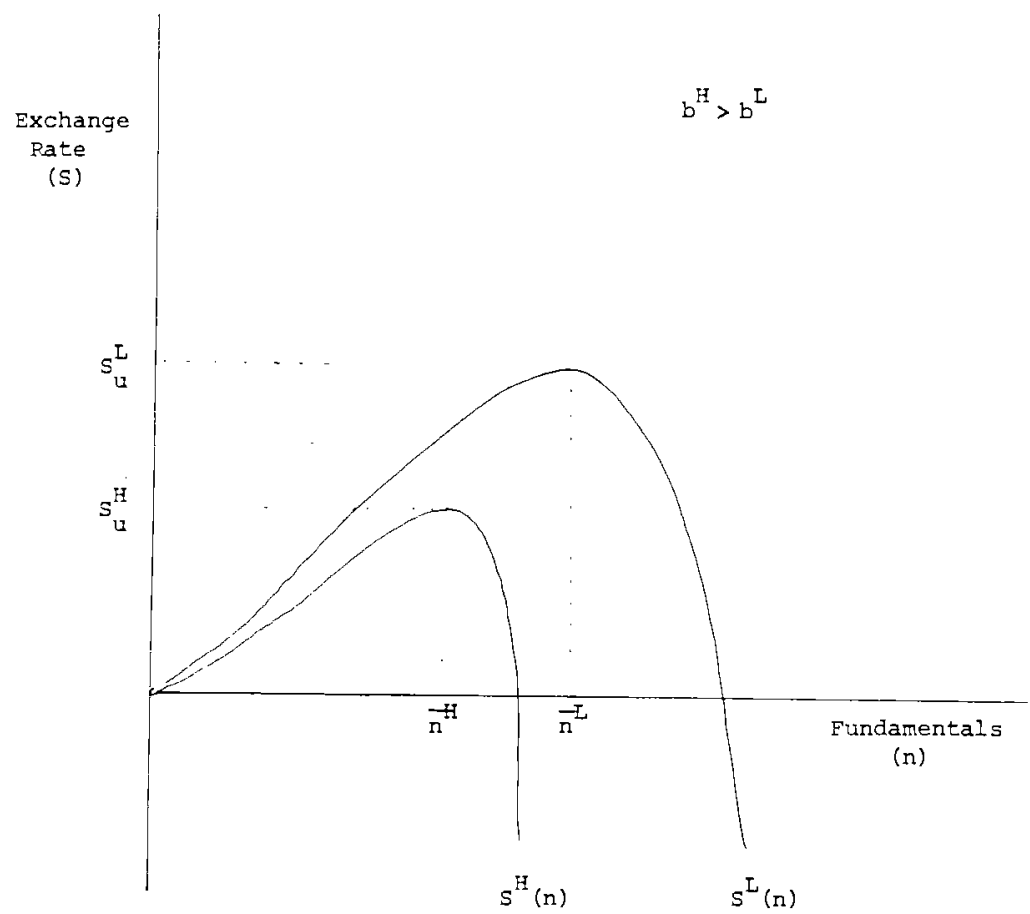

FIGURE 3: Exchange Rates with High and Low Intervention Probabilities 


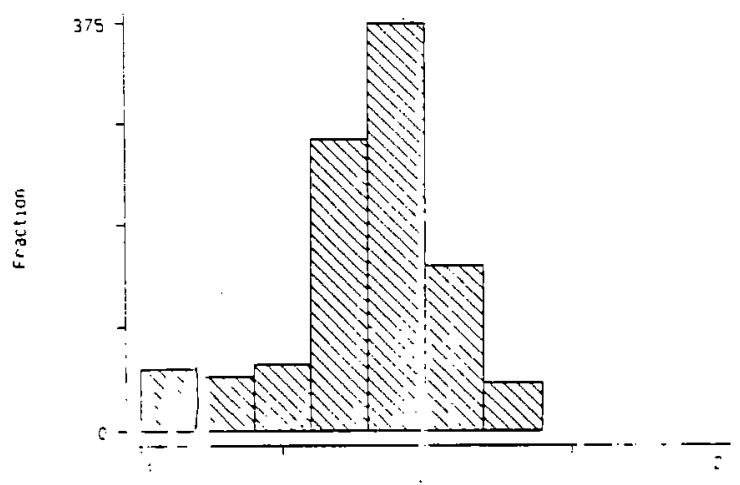

Histogram of Funcamentals with Intervention. b. = 50

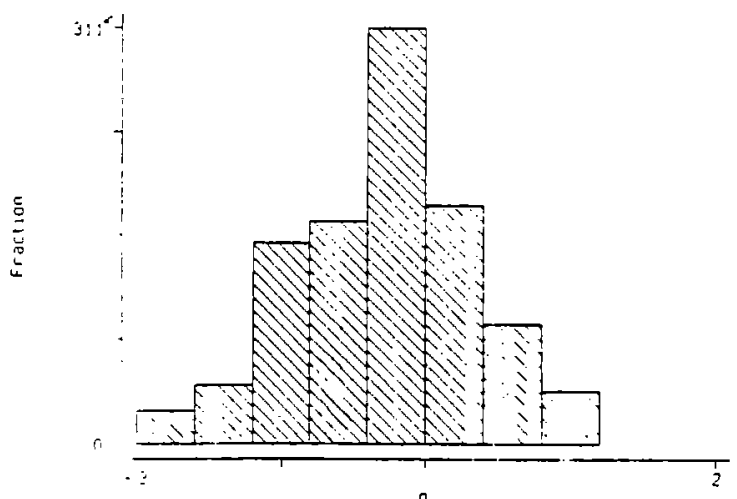

Hustogram of Fundamentals with Intervention. $D=20$

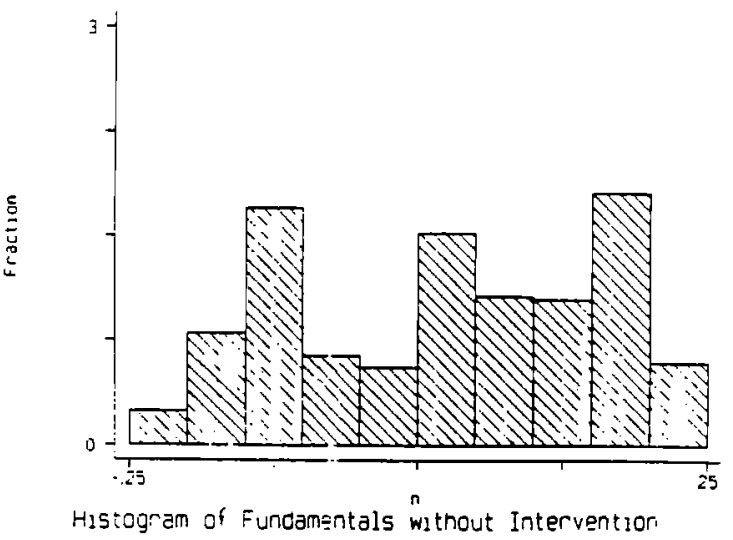

FIGURE 4 

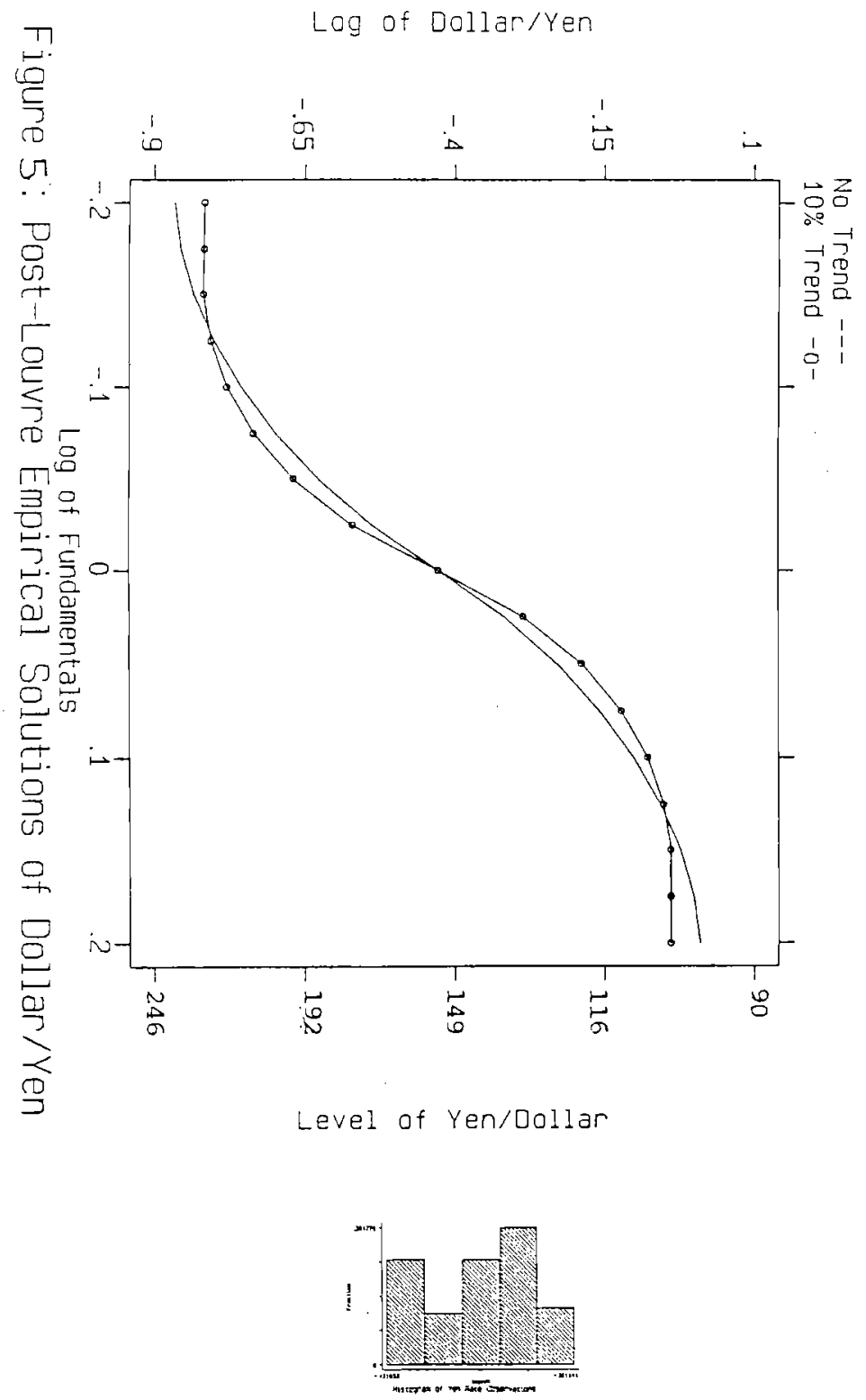


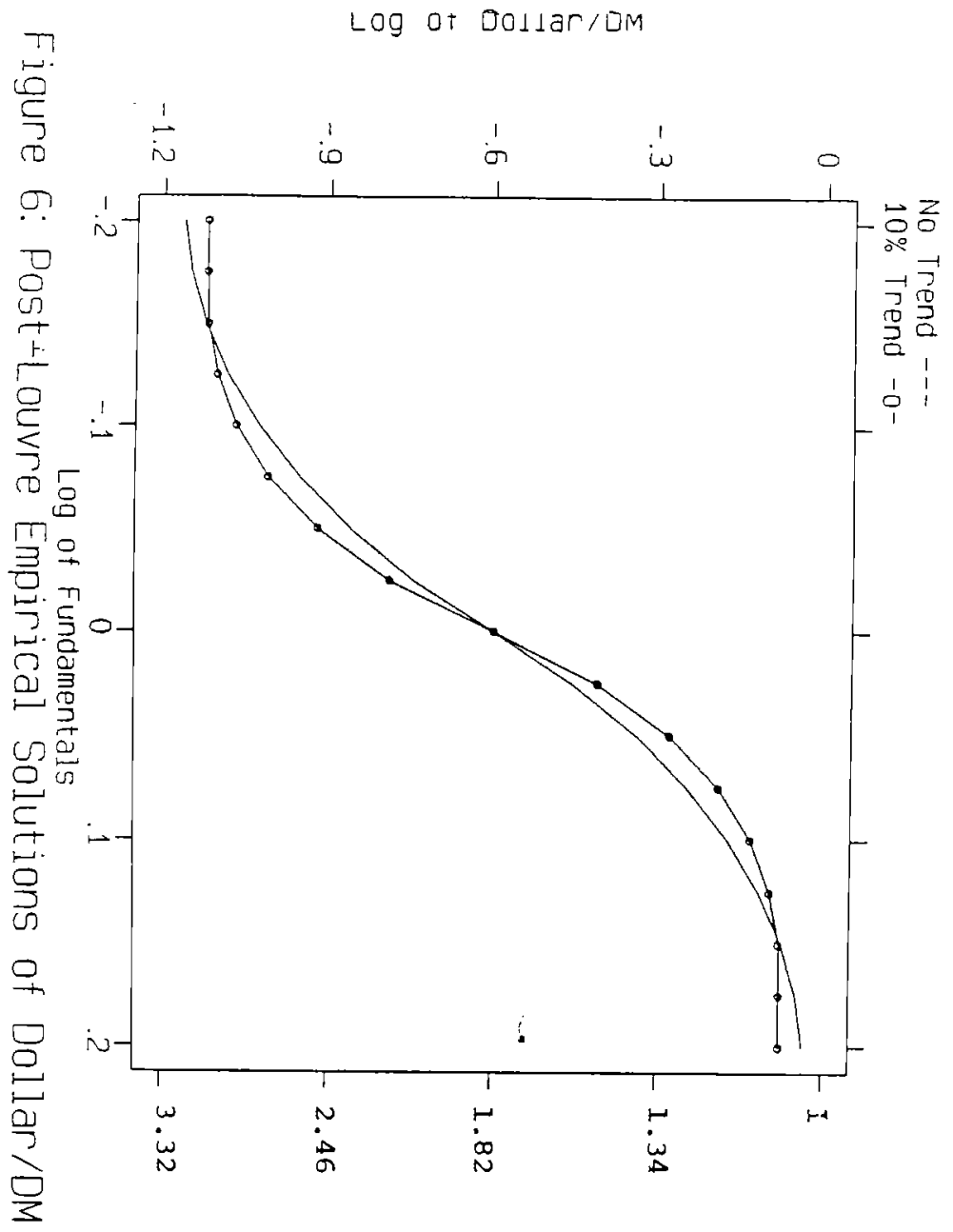

Level of DM/Dollar

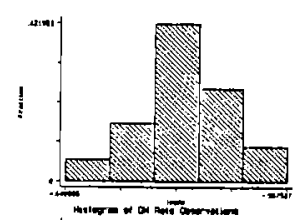

